\title{
Multiple myeloma: Development of plasma cell sarcoma during apparently successful chemotherapy
}

\author{
J. M. HOLT AND A. H. T. ROBB-SMITH \\ From the Nuffield Department of Medicine and Gibson Laboratories of the Radcliffe Infirmary, Oxford
}

SYNOPSIS Three patients with multiple myeloma who developed a plasma cell sarcoma during apparently successful chemothapy are described. It is postulated that the chemotherapy induced the sarcomatous change.

There is now evidence to suggest that impaired immunological protection predisposes to the development of malignant disease of the lymphoreticular tissue. A high incidence of reticulosarcoma has been recognized amongst patients undergoing prolonged treatment with immunosuppressive agents following organ transplantation (Doak, Montgomerie, North, and Smith, 1968) and a higher than expected proportion of patients with congenital hypogammaglobulinaemia develop tumours of the lymphoid system (Medical Research Council, 1969). Multiple myeloma is characterized by the loss of normal immune globulin production. The purpose of this paper is to report the development of plasma cell sarcoma in three patients during apparently successful chemotherapy of multiple myeloma, and to speculate that treatment may have brought about a further impairment of immune protection against malignancy.

These three patients were seen during the period 1965 to 1969 when some 100 patients with multiple myeloma were under treatment.

\section{Case I (RI reg no. 114357)}

A 55-year-old woman was investigated because of pain in the back. Radiographs of the bones showed widespread lytic lesions typical of myeloma and a marrow aspirate contained large numbers of atypical plasma cells confirming the diagnosis. She was treated initially by radiotherapy to the lumbar spine with transient improvement, but after two months she developed pleuritic chest pain and symptoms of pneumonia. Investigations at this stage were as follows: $\mathrm{Hb} 9.6 \mathrm{~g} / 100 \mathrm{ml}$, WBC 5900 per c mm, platelets normal on film, reticulocytes $5 \%$; ESR 112

Received for publication 12 June 1973. $\mathrm{mm}$ in one hour; blood urea $20 \mathrm{mg} / 100 \mathrm{ml}$, total serum proteins $7.8 \mathrm{~g} / 100 \mathrm{ml}$ (albumin $3.5 \mathrm{~g} / 100 \mathrm{ml}$ ); a sharply defined band in the beta area on cellulose acetate electrophoresis; Bence-Jones proteinuria, type $\mathbf{k}$, in low concentration. Immunoelectrophoresis: IgA myeloma protein; immunoglobulin concentration, IgA $600 \mathrm{mg}$, IgG $400 \mathrm{mg}$, IgM 60 $\mathrm{mg} / 100 \mathrm{ml}$. The chest infection was controlled by tetracycline and treatment with cyclophosphamide, $100 \mathrm{mg}$ daily, was begun. After three months, during which the pain had regressed and her general health improved, no significant change in the peripheral white cell count or platelet count had occurred and the dose was increased to $150 \mathrm{mg}$ daily. By the sixth month no myeloma protein could be detected on electrophoresis (fig 1) and the previously depressed IgG level had increased to a normal concentration (fig 2). Apart from minor chest infections she remained well. Ten months after the commencement of therapy, during which time she had received a total of approximately $30 \mathrm{~g}$ cyclophosphamide, her health deteriorated suddenly and she developed signs of cord compression. At the time of death four weeks later no Bence-Jones protein could be detected in the urine and there had been no reappearance of the myeloma protein (fig 1). However, the concentration of IgG was once more depressed (fig 2).

At necropsy (RIPM 1275/65) there was moniliasis of the mouth and pharynx and bilateral bronchopneumonia with old pleural adhesions. A large mass of firm white tumour was replacing the right psoas muscle and extended round the inferior vena cava and right common iliac artery; it was also compressing the right renal pelvis and surrounding but not infiltrating the right adrenal and was contiguous to the vertebral body. There was no lymph node enlargement, the spleen was small $(90 \mathrm{~g})$, and there was no abnormality of the liver. The third and fourth 
F.T.

22.12 .64

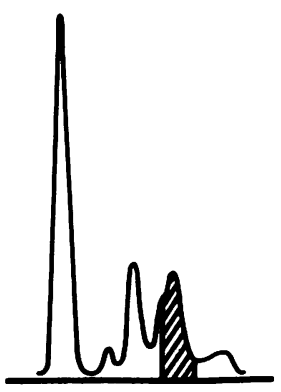

23.6 .65

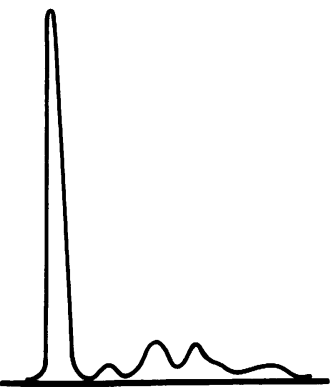

After 6 months

\section{F.T. \& Age 55.}

( IgA k. myeloma )

\section{Treatment.: CONTINUOUS CYCLOPHOSPHAMHDE}

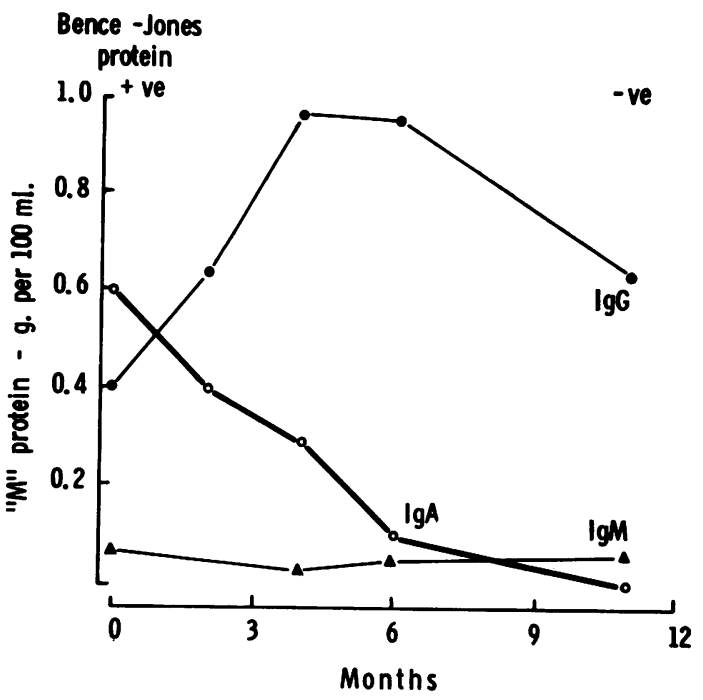

Fig 2 Case 1: graphic representation of change in levels of IgG and IgM protein.

lumbar vertebrae had collapsed with evidence of osteolysis.

\section{HISTOLOGY}

The tumour is a plasma cell reticulosarcoma which is infiltrating muscle and surrounding nerve roots (fig 3a) The tumour cells range from 6 to $20 \mu$ in diameter with a large pachychromatic nucleus and a prominent nucleolus. The larger cells are often bi- or multinucleate and show frequent mitoses, while some of the smaller cells have an eccentric nucleus with a radiating chromatin pattern and a prominent nucleolus resembling the myeloma plasma cell; the
29.11 .65

Fig 1 Case 1: immunoelectrophoresis showing disappearance of IgA myeloma protein. cytoplasm is sometimes pyrinophilic (fig 3b). A 을 section of vertebra showed tumour extending into the periosteum while the underlying marrow was $\infty$ somewhat hypoplastic, with occasional foci of plasma $\frac{\mathbb{O}}{\square}$ cells, some being immature, but none showing the abnormal characters of the tumour cells. However, a section of rib showed sheets of abnormal plasma cells interspersed with giant cell forms. The other $\vec{\theta}$ tissues were not abnormal apart from some bronche w pneumonia and pyelonephritis but there was evidence of myeloma nephropathy.

\section{Case 2 (RI reg no. 402315)}

A 65-year-old woman became increasingly short of breath over a period of three weeks. Her previous $\frac{9}{3}$ health had been good and apart from moderate loss of weight she would admit to no other symptoms. On examination she looked ill and there was central cyanosis and tachypnoea. There were signs of con-? solidation over the left lower lobe confirmed by a radiograph of the chest, but she had no fever. Investigations were as follows: $\mathrm{Hb} 10.8 \mathrm{~g} / 100 \mathrm{ml}$, MCHC $30 \%$, WBC 13500 per c mm $(72-88 \%$ neutrophils, $3-10 \%$ eosinophils), ESR 64 , platelets normal; latex positive, DAT 1024, ANF negative. $\rightarrow$ Detailed serological, bacteriological, and virological investigations failed to delineate the aetiology of the $N$ pulmonary disease and open lung biopsy was performed. This showed (RISH 8106/66) considerable 0 fibrous thickening of the alveolar walls in which $\mathrm{\omega}$ there were foci of lymphoid cells but very few plasma cells; there was was a proteinaceous intra-alveolar $\varrho$ exudate rich in alveolar phagocytes. These appear- $\mathbb{D}$ ances were interpreted as an interstitial pulmonary $\stackrel{\mathcal{P}}{+}$ fibrosis with desquamative pneumonitis, and treat- 0 ment with prednisolone, $40 \mathrm{mg}$ daily, was begun. Her condition improved quickly and after three 


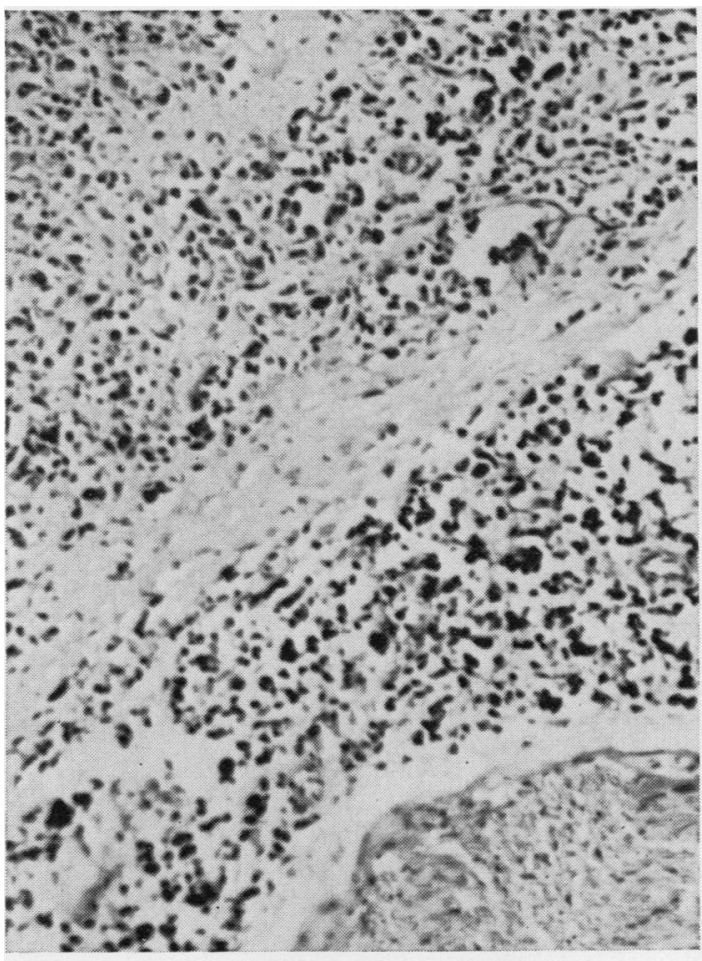

Fig 3a

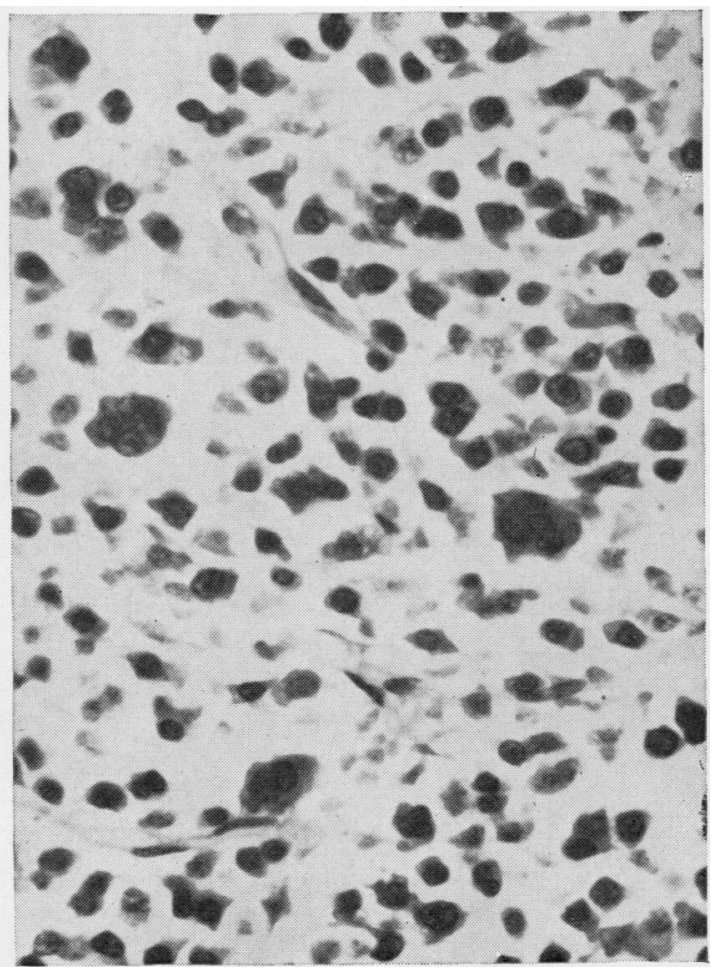

Fig $3 b$

Fig 3 Case 1: (a) tumour mass replacing right psoas muscle $(\times 120)$. The plasma cell reticulosarcoma can be seen to be infiltrating muscle and surrounding nerve fibres. (b) High power $(\times 480)$ showing the variable character of the tumour cells.

months she was no longer short of breath and there had been considerable resolution of the lung lesions radiographically. The ESR fell to $6 \mathrm{~mm}$ in one hour and the latex test reverted to negative, but she continued to have a mild neutrophil leucocytosis. During the course of the initial investigations, the bone marrow was found to contain a few atypical plasma cells that suggested multiple myeloma. A small number of lytic lesions on skull radiographs supported this diagnosis but the serum proteins were normal (total $6.5 \mathrm{~g} / 100 \mathrm{ml}$, cellulose acetate electrophoresis normal). Immunoglobulin concentrations were normal-IgG 1300, IgM $47 \mathrm{mg} / 100 \mathrm{ml}$-and no Bence-Jones protein was detected in the urine by conventional testing.

After a further six months during which time she had been free from symptoms, she developed pain in the back. Radiographs of the lumbar spine showed generalized decalcification and compression fractures. The lytic lesions in the skull were larger and myeloma was confirmed when Bence-Jones protein, type $\mathbf{L}$, was detected in low concentration in the urine. By this time there had been in addition a sharp fall in the concentration of IgG (IgG 600, IgA 120 , IgM $30 \mathrm{mg} / 100 \mathrm{ml}$ ) and the marrow still contained a number of atypical plasma cells of the myeloma type. She was treated initially by radiotherapy to the lumbar spine and one month later began treatment with melphalan. During the succeeding four months she received approximately $600 \mathrm{mg}$ in a daily dose that varied between 4 and $10 \mathrm{mg}$. Treatment was then suspended because of marrow suppression but her health had improved, she was free from pain, and had resumed a normal life.

During the following 12 months she continued to enjoy good health and further courses of melphalan were prescribed though these had to be curtailed because of white cell and platelet depression. Twentytwo months after the commencement of treatment, by which time she had received $700 \mathrm{mg}$ melphalan, Bence-Jones protein could no longer be detected in the urine. However, the concentration of immune 


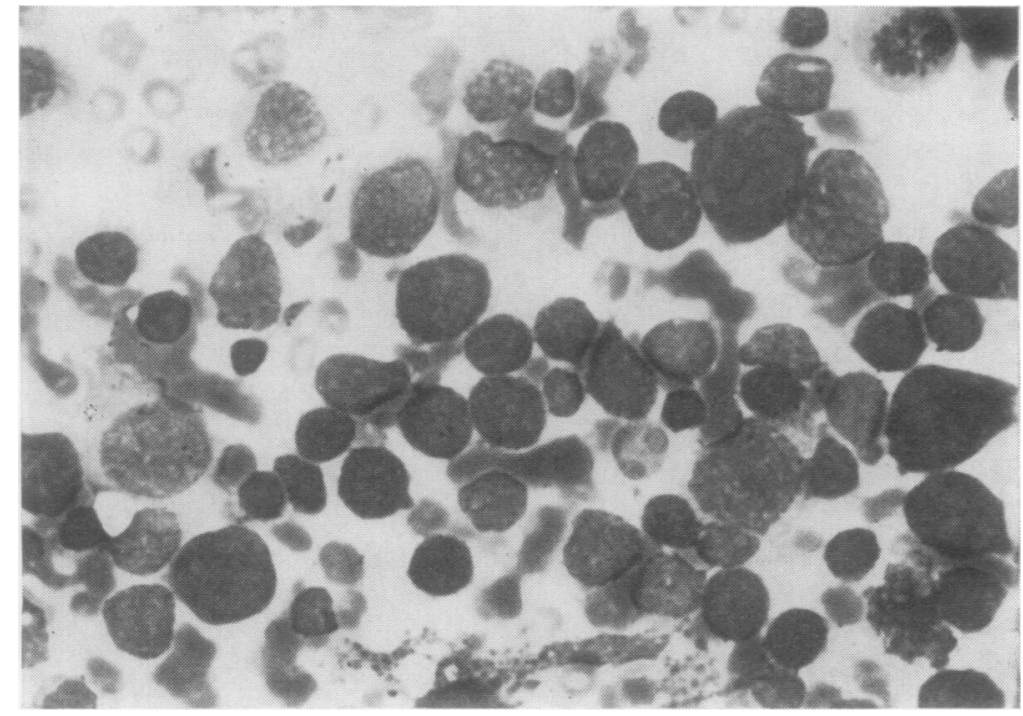

Fig 4 Case 2: sternal marrow shortly before death $(\times 480)$. Sheets of primitive reticulum cells.

globulins had declined further: IgG 480, IgA 40, IgM $13 \mathrm{mg} / 100 \mathrm{ml}$. At this stage her health suddenly deteriorated and she developed severe shortness of breath due to a large pleural effusion. Two weeks later she died having developed soft tissue lesions in the lung, anterior chest wall, and abdomen. The bone marrow was strikingly different from that observed one and two years previously and contained large number of primitive reticulum cells that suggested a diagnosis of reticulosarcoma (fig 4).

At necropsy (RIPM 1143/69) there was a soft tissue swelling $10 \mathrm{~cm}$ in diameter overlying the left anterior chest wall in the region of the fourth to sixth ribs. Internally the left pleural cavity was partially obliterated by plaques of soft, whitish tumour tissue which was adherent to the lung surface and the parietal pleura, eroding the ribs and extending under the left breast. There was a straw-coloured effusion of about $600 \mathrm{ml}$. The left lung was rather shrunken and there were scattered tumour deposits on the surface of the lung, pleura, and pericardium. The right lung and other thoracic organs were not remarkable.

In the abdomen the gastrointestinal tract was not abnormal, the liver was slightly enlarged $(1684 \mathrm{~g})$ but showed no tumour deposits, though there were some suspicious areas in the pancreas. The spleen $(150 \mathrm{~g})$ showed no abnormalities. The pelvis of the left kidney was infiltrated by a mass of tumour tissue which extended into the renal substance, but the right kidney and other genito-urinary organs were normal. The endocrines were normal. The lymph nodes in the left axilla were enlarged and infiltrated with tumour, but other nodes were natural. There $\mathbb{\Phi}$ were areas of erosion in the skull and the ribs on the left side were infiltrated by tumour as were tBe lumbar vertebrae and femur.

H IS T O L OGY

The pleural tumour is a plasma cell reticulosarcoma (fig 5a, b, c) similar to that of case 1. It is infiltrating the lung and thoracic muscles; the underlying lung is fibrotic.

The renal tumour is similar in character and the kidney shows some pyelonephritis and proteinaceous casts in the collecting tubules. The axillary lymph node is infiltrated by reticulosarcoma. The liver shows no abnormality but in the spleen there are foci of tumour cells. The bone marrow is infiltrated by the tumour which is clearly demarcated from the normal patterned marrow in which there are moderate numbers of myeloma plasma cells (fig $6 \mathrm{a}, \mathrm{b}$ ).

\section{Case 3 (RI reg no. 165351)}

A 70-year-old man complained of pain in the right $\widetilde{N}$ hip and lower back for three months and because the $N$ ESR was elevated to $105 \mathrm{~mm}$ in one hour, multiple N myeloma was suspected. Radiographs of the spine ${ }_{\sigma}^{\mathcal{O}}$ and pelvis showed only generalized decalcification, but the diagnosis was confirmed when marrow aspir- $O$ ation showed a diffuse infiltration with abnormal $\stackrel{\Phi}{\mathcal{D}}$ plasma cells. Investigations at this stage were as follows: $\mathrm{Hb} 12.4 \mathrm{~g} / 100 \mathrm{ml}$, WBC 8000 per c mm, platelets 327000 per c mm; blood urea 44 ; total serum proteins $8.5 \mathrm{~g} / 100 \mathrm{ml}$ (albumin $3.3 \mathrm{~g} / 100 \mathrm{ml}$ ), $\frac{\Omega}{\mathbb{Q}}$ 


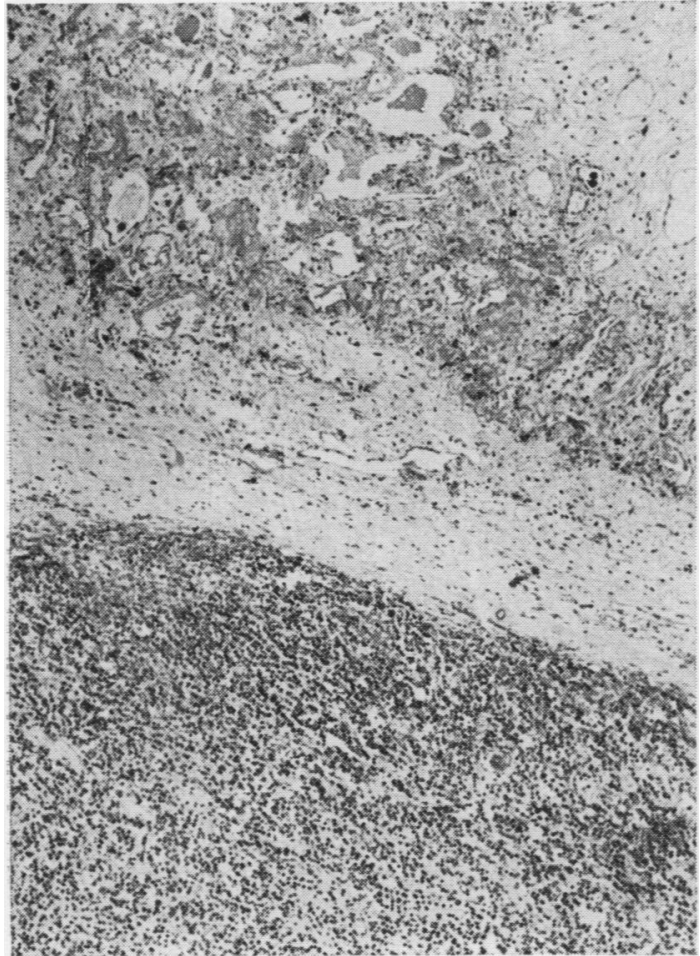

Fig 5a The low power $(\times 48)$ shows the pleura invaded by tumour while the underlying lung is fibrotic.

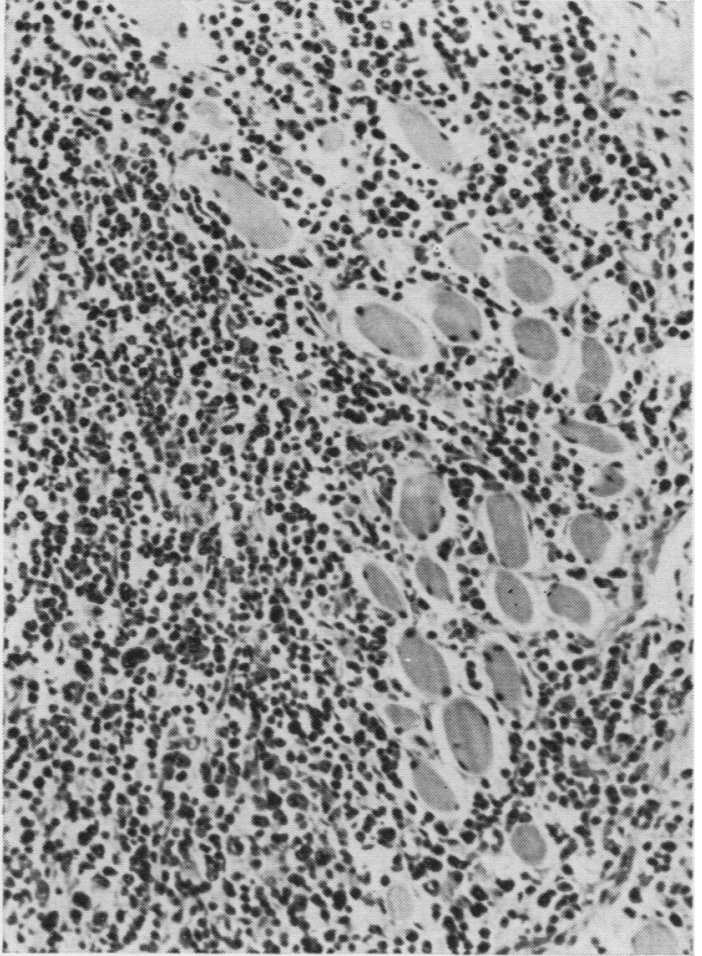

Fig $5 \mathrm{~b}$ The medium power $(\times 120)$ shows the tumour cells infiltrating the muscle.

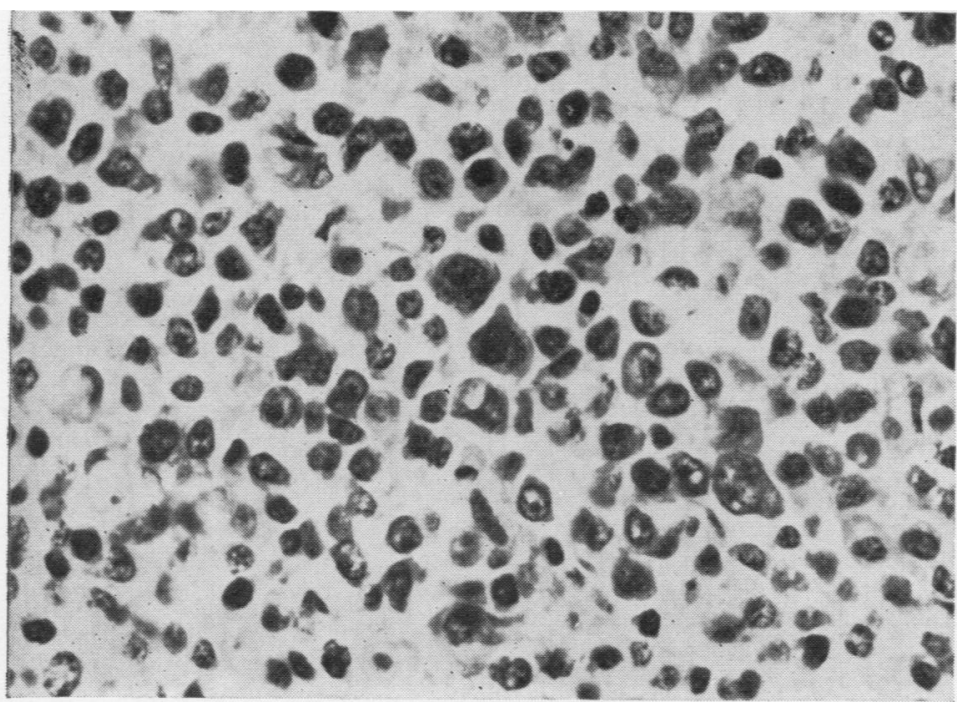

Fig 5 Case 2: lung with pleural tumours.

Fig 5c The high power $(\times 480)$ shows the character of the tumour cells. 


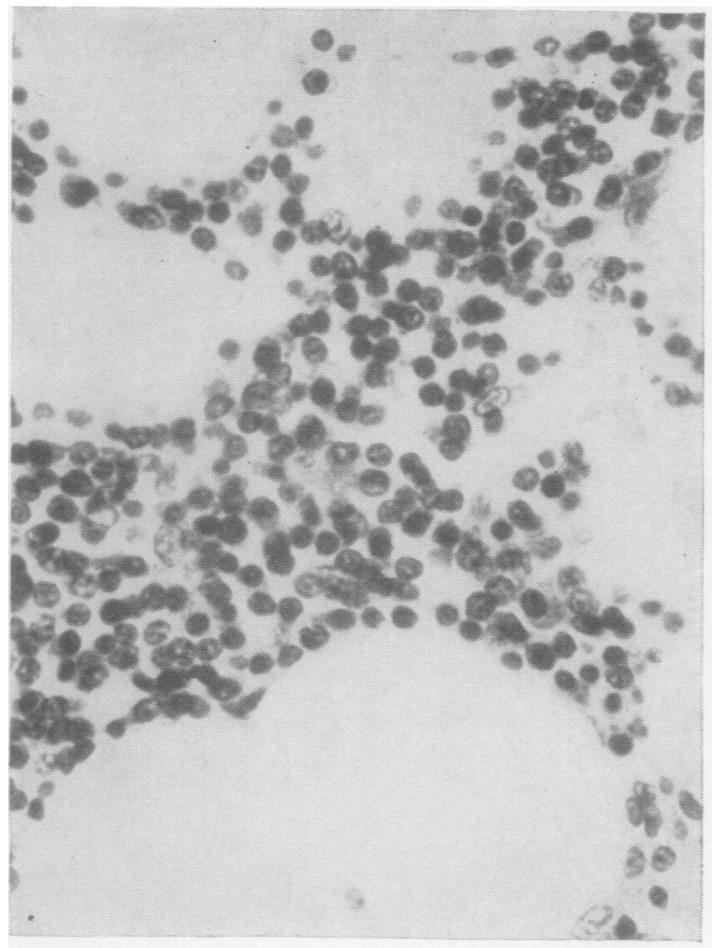

Fig 6a

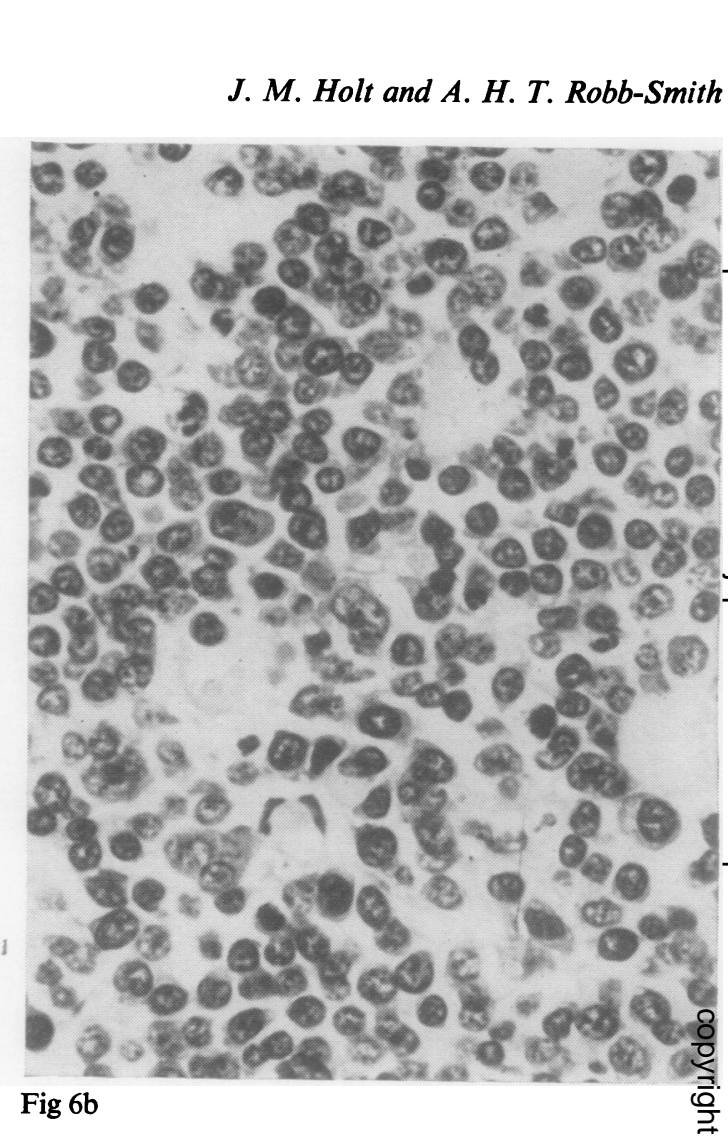

Fig $6 b$

Fig 6 Case 2: bone marrow $(\times 480)$. The contrast is apparent between the 'normal' marrow (a) in which there are a moderate number of myeloma plasma cells, and the nodules (b) of plasma cell reticulosarcoma.

sharply defined band in gamma area on cellulose acetate electrophoresis (fig 7). Immunoelectrophoresis showed IgG myeloma protein, and immunoglobulin concentrations were: IgG 2500, IgA 30, IgM $20 \mathrm{mg} / 100 \mathrm{ml}$; Bence-Jones proteinuria, type $\mathrm{K}$.

Treatment with cyclophosphamide, $150 \mathrm{mg}$ daily, was begun but therapy was withdrawn after five weeks because of neutropenia (WBC 900 per c mm). $\overrightarrow{\overrightarrow{0}}$ Cyclophosphamide was later introduced in a smaller 3 dose and by six months his condition had improved $\rightleftharpoons$ to such an extent that he was able to dig his garden, ride a bicycle, and resume his normal life. One year after diagnosis myeloma protein was no longer detectable and only occasional plasma cells were

J.P.

19.11 .64

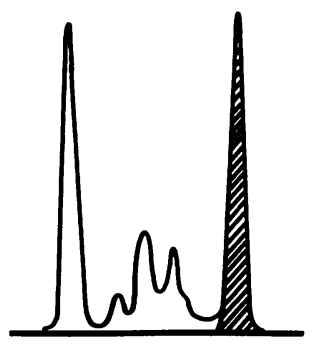

22.2 .66

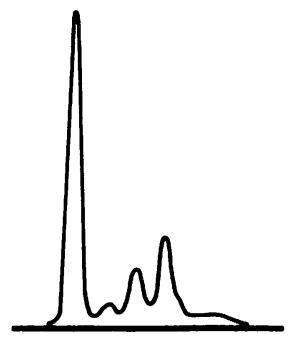

After 2 years
13.11 .67

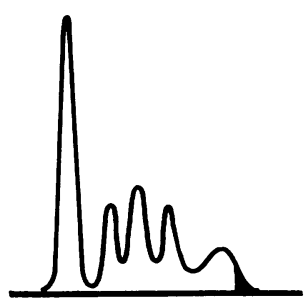

After 3 years
Fig 7 Case 3: immunoelectrophoresis showing a sharply defined $\mathrm{N}$ band of IgG protein which disappeared under treatment although $\mathrm{N}$ terminally a trace of myeloma protein returned. 


\section{J.P. of Age 70 (IgG k myeloma)}

ireatment : CONTINUOUS CYCLOPHOSPHAMIDE
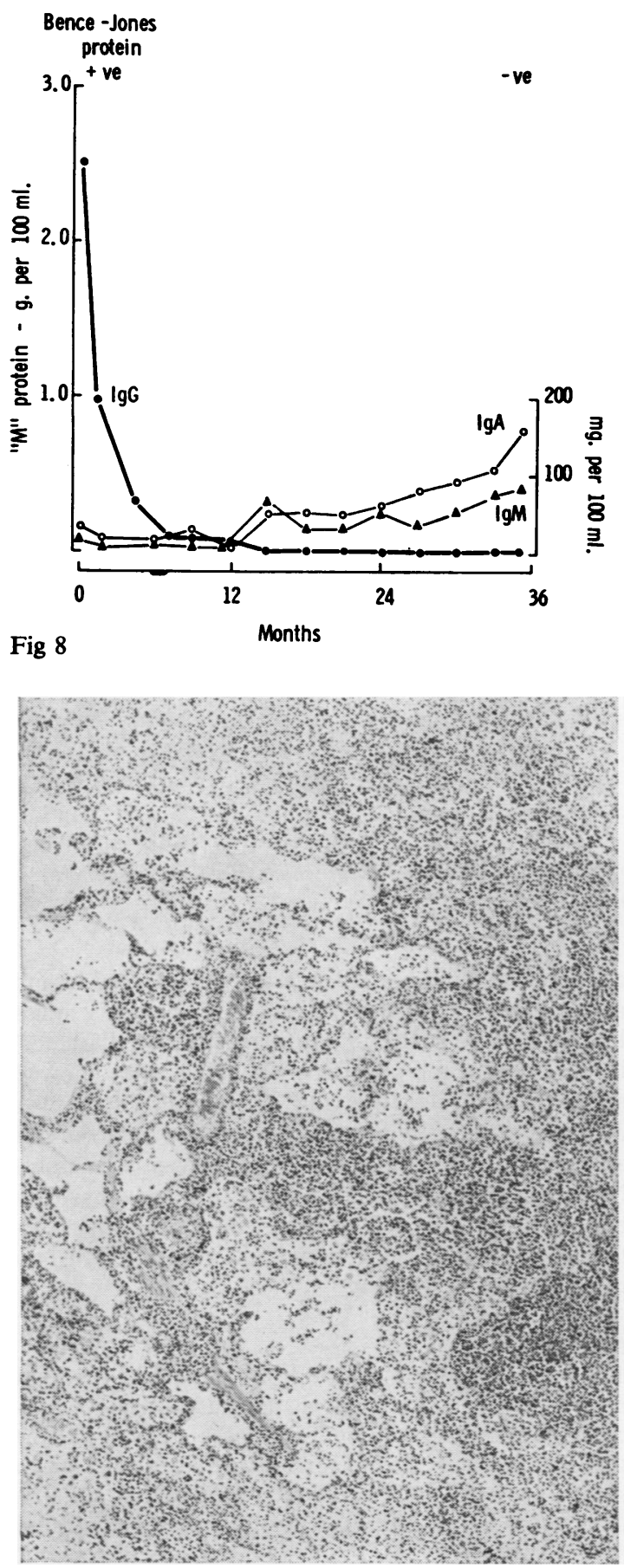

Fig 9a
Fig 8 Case 3: graphic representation of change in levels of immunoglobulins during the course of the illness.

Fig 9 Case 3: pulmonary tumours (a) The low power $(\times 48)$ shows the general pattern of the tumour deposits in the lung. (b) The high power $(\times 480)$ shows the character of the plasma cell reticulosarcoma.

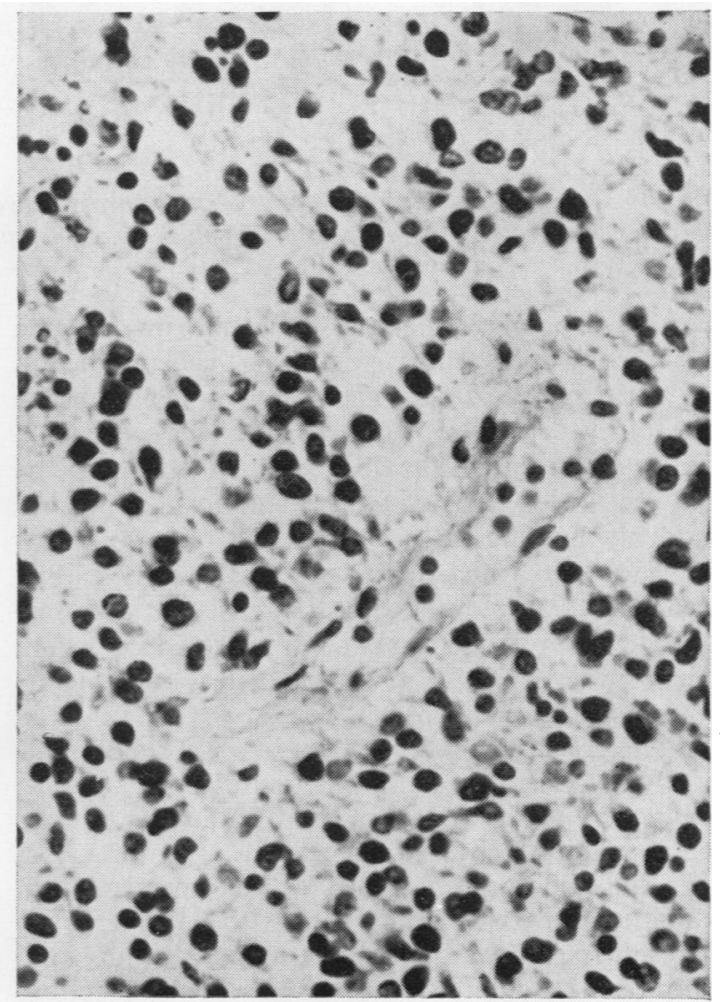

Fig 9b 


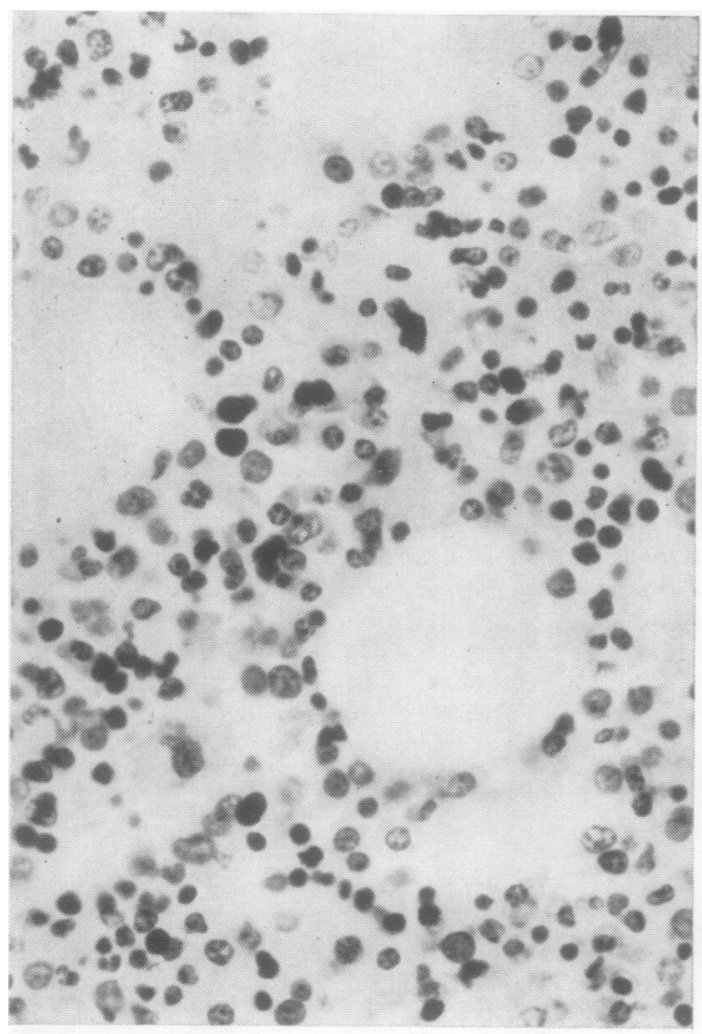

Fig 10a

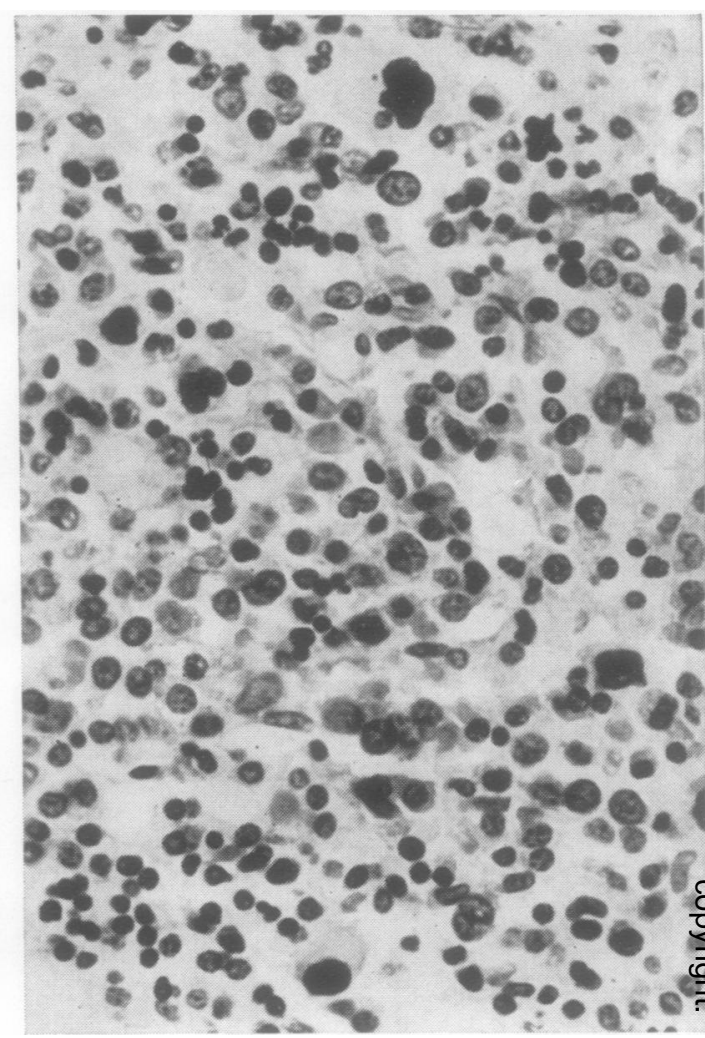

Fig $10 b$

Fig 10 Case 3: bone marrow $(\times 480)$. The contrast between $(\mathrm{a})$ the 'normal' marrow in which there are myeloma plasma cells, and (b) the foci of atypical plasma cells is apparent.

seen on examination of the bone marrow. During the second and third years his general health remained good and some improvement in the previously depressed IgA and IgM levels occurred (fig 8). At the end of the third year, by which time he had received a total of $60 \mathrm{~g}$ cyclophosphamide, he suddenly became ill and developed numerous soft tissue tumours which increased in size rapidly leading to his death 36 months after diagnosis. At this time a trace of myeloma protein was detected on serum electrophoresis (fig 7), but Bence-Jones protein was not present in the urine.

At necropsy (RIPM 88/68) there was a small rightsided pleural effusion and in the substance of both lungs there were several rounded firm white tumour massess up to $3 \mathrm{~cm}$ in diameter.

In the abdomen there was a large mass of hard white tumour tissue filling the pelvis and adherent to the right pelvic wall; it was involving the inguinal lymph nodes and infiltrating the pelvic colon, rectum, and bladder. The liver (1450 g) and spleen (186 g) appeared normal and there were no enlarged lymph nodes other than those involved in the pelvic mass but there was a small tumour mass (1 $\mathrm{cm}$ in diameter) in the body of the pancreas. The left kidney showed some cortical scarring and the right kidney was atrophic with a hydronephrosis and a hydroureter above the tumour mass. There was a massive haemorrhage in the right adrenal associated with a renal vein thrombus. The bones showed osteoporosis and widespread haemorrhagic marrow but no obvious tumour masses.

\section{HISTOLOGY}

The tumour infiltrating the lung, pancreas, inguinal nodes, and pelvic mass is a plasma cell reticulosarcoma similar to that seen in the other two cases, but there are fewer giant cell forms (fig 9a, b). The spleen $\cong$ shows an excess of myeloma type plasma cells as does the marrow and in addition there are small foci of large atypical plasma cells in the bone marrow but no real tumour nodules (fig $10 \mathrm{a}, \mathrm{b}$ ). 


Author Case Summary

James and Turner (1952)

Case Summary

Newman et al (1952)

Female aged 66. Myelomatosis presented with gross involvement of parotid and cervical lymph nodes. Treated with radiotherapy and stibamidine. Duration 7 months. Necropsy: medullary myelomatosis with gross infiltration of parotid-cervical region, pancreas and mesenteric lymph nodes. Histology: 'plasma sarcoma'.

Male aged 55. Myelomatosis (possibly IgA) with plasma cell leukaemia. Duration 2 months. Necropsy: medullary myelomatosis. Intraabdominal mass, $10 \times 15 \mathrm{~cm}$, arising from pelvis replacing rectus abdominis muscle. Extensive invasion of thoracic and abdominal viscera. Histology: poorly differentiated plasma cell tumour 'in character analogous to a lymphosarcoma'.

Sandkühler and Roemheld (1957)

Case 2. Female aged 42. Myelomatosis (possibly IgG). Treated with radiotherapy and urethane. Duration 11 months. Necropsy: medullary myelomatosis, myeloma nephropathy Numerous pulmonary and diaphragmatic tumour nodules. Histology: plasma cell sarcoma.

Kernen and Meyer (1966) Male aged 67. Found to have a tumour in left upper lobe of lung on routine radiography. Further investigation revealed myelomatosis (IgG). Pulmonary tumour resected. Histology: malignant plasmocytoma with lymph node metastases. Died 6 months later with coronary thrombosis.

Okano et al (1966) Male aged 40. Myelomatosis (IgG) treated with radiotherapy and urethane. Initial improvement, but after 14 months relapse with skin tumours and abdominal mass. Transient improvement with radiotherapy, cyclophosphamide, and nitrogen mustard. Duration 3 years. Necropsy: medullary myelomatosis. Large peivic mass. Widespread lymph node involvement and deposits in mesentery, kidney, heart, and lungs. Histology: Plasmacytic reticulum cell sarcoma.

River and Schörr (1966)

Case I. Female aged 62. Myelomatosis (IgG) treated with cyclophosphamide and melphalan with good response. Two years later developed skin tumour. Duration 2 years. Necropsy: medullary myelomatosis. Numerous skin and subcutaneous tumours. Histology: poorly differentiated plasmocytoma.

Case II. Male aged 46. Myelomatosis (IgL [Bence-Jones]) treated with cyclophosphamide and melphalan. After one year developed skin tumours. Duration 1 year. Necropsy: Medullary myelomatosis. Myeloma nephropathy. Tumours in skin and subcutaneous tissue. Histology: plasma cell reticulosarcoma.

Craft (1967) Female aged 41. Myelomatosis (IgG) treated with radiotherapy and cyclophosphamide with good clinical and serological response, though there was evidence from time to time of marrow reactivation. Three years after the onset of treatment developed a mass in right breast shown to be a plasmacytoma. Transient response to radiotherapy but a large pelvic mass developed. Duration 3 years 2 months. No necropsy. Photomicrographs of breast tumour show immature and bizarre plasma cells very different from original sternal puncture.

Case 5. Male aged 49. Myelomatosis (probably IgA) initially found to have a retroperitoneal plasmocytoma which responded well to urethane with return of blood chemistry to normal. Four years later gross lymph node enlargement and abdominal mass with increase of abnormal globulins although the bone marrow was hypoplastic. Duration $4 \frac{1}{2}$ years. Limited necropsy. Massive infiltrating abdominal tumour causing ureteric obstruction. Histology: immature type plasmocytoma.

Male aged 46. Myelomatosis (IgA) treated with melphalan with remission, but after 18 months developed skin nodules and enlarged lymph nodes and over the next six months mediastinal and pelvic masses. Outcome not reported. Histology: poorly differentiated plasmocytoma.

Male aged 60. Myelomatosis (IgG) treated with cyclophosphamide with a good clinical response and regression of osteolytic lesions. Three years after the onset of treatment, developed respiratory symptoms and radiological evidence of pulmonary masses. Duration 3 years and 1 month. Necropsy revealed tumour masses in lungs, intestines, liver, kidney and mesentery which had the histological characters of a reticulosarcoma. Myeloma cells were only seen in the bone marrow.

Table Cases of myelomatosis with sarcomatous change

\section{Discussion}

These three cases of myelomatosis, which had responded to chemotherapy and were in remission, each developed a reticulosarcoma, in which the main tumour mass was in extralymphoreticular tissue. In all three cases the bone marrow was hypoplastic with small foci of myeloma plasma cells, but in cases 1 and 3 there were also foci of abnormal plasma cells resembling the tumour, while in case 2 there were tumour deposits infiltrating but distinct from the normal marrow.

This association is certainly uncommon, but it is difficult to determine how uncommon. Until about 30 years ago it was generally believed that myelomatosis was essentially a disease restricted to the bone marrow, though Pappenheim, in 1907, had stated that 'myelomatosis is not a disorder peculiar to the bone marrow, but is like leukaemia and pseudo- leukaemia, a disease of the whole haemopoietic system which appears to affect at first or primarily the bone marrow'. However about 1950 there were a number of reviews (eg, Churg and Gordon, 1950; Hayes, Bennett, and Heck, 1952) which showed that at postmortem examination there was extraosseous involvement in about $70 \%$ of cases of myelomatosis, the organs most frequently affected being the liver, spleen, and lymph nodes, but plasma cell infiltrates had on occasion been detected in almost every organ, the kidney and the lung being the commonest extralymphoreticular sites. The involvement was usually only detected microscopically, but in a minority of cases small nodules were observed in the viscera. It was at this time that Hellwig (1943), Carson, Ackerman, and Maltby (1955), and Dolin and Dewar (1956) showed that the so-called solitary plasmocytoma, whether intra- or extraosseous, might remain localized for a number of years, 'transform' into multiple myelomatosis or behave as an invasive 
tumour with tissue destruction and distant metastases. However, in the various reports there was seldom any indication whether the tumour should be classed on morphological grounds as a truly invasive malignant sarcoma or a progressive hyperplastic process analogous to a leukosis and usually the non-committal designation of 'lymphoma' was adopted. On the other hand it was recognized there was a considerable range in cellular differentiation in myelomatosis, the cell types varying from mature plasma cells to immature pleomorphic cells with a large nucleus, which might be multinucleate, but again there was little attempt to correlate the cytology with the tumour characters or the natural history of the disease.

In 1961 Aherne made a detailed study of 69 cases of myelomatosis observed between 1945 and 1960 and of those examined at necropsy all showed plasma cell infiltration in the lymphoreticular tissue and a few showed deposits in lung and kidney, but there were no gross tumours of a sarcomatous character; on the other hand Innes and Newell (1961) in a review of 188 cases of myelomatosis stated that 10 of the cases at necropsy were found 'to have gross extramedullary tumour masses in the abdominal or thoracic cavities' but no further details were provided.

Waldenström (1964), in his account of 70 cases of myelomatosis treated with melphalan, mentioned, without any details, a patient with plasma cell leukaemia who went into complete remission but subsequently developed a reticulosarcoma with marked Bence-Jones proteinuria, while Reinshagen (1966) in describing a case of myelomatosis which presented with gross axillary lymph node enlargement invaded by poorly differentiated plasma cells, stated that in a series of 21 cases of myelomatosis and plasma cell leukaemia coming to necropsy between 1953 and 1965 there were two cases with reticulosarcomatous change. Pasmantier and Azar (1969) analysed 57 cases of myelomatosis about the same period and found that a third had gross spread to distant sites, which they classed as stage III, and over half of these were poorly differentiated neoplasms; on the other hand the cases with longest survival were those with stage III spread and poor cellular differentiation.

In addition there are a number of individual case reports of myelomatosis with large extraskeletal tumours (see table) which are clearly sarcomatous, quite apart from cases of medullary plasma cell reticulosarcoma such as that of Wuketich and Siegmand (1961).

It was in 1964 that it was first suggested that cytostatic drugs might induce reticular hyperplasia or reticulosarcomata (Chiari, 1964; Gross, 1964;

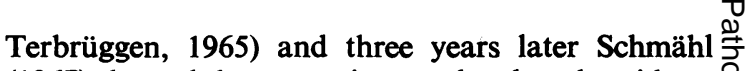
(1967) showed that rats, given cyclosphosphamide or 을 trenimon (triaziquone) in doses comparable to those $\overrightarrow{\vec{F}}$ used in man, developed neoplasms in 15 to 20 months. The cyclophosphamide group, which had received $\frac{\mathrm{C}}{\mathrm{C}}$ $750 \mathrm{mg} / \mathrm{kg}$ over a year, developed tumours in $22 \% \frac{\bar{\sigma}}{\bar{\omega}}$ of the animals (six abdominal sarcomata, one malig- $\frac{\vec{\sigma}}{\sigma}$ nant lymphadenosis, one myeloid leukaemia, one $\varrho$ epithelioma of skin) and the trenimon-treated के animals were very similar, whereas no malignant $\vec{\circ}$ tumours arose in the controls. Edwards and Zawadzki $\overrightarrow{-}$ (1967) reported a case of myelomatosis in a man who $\vec{O}$ had been under successful treatment with radiotherapy, urethane, and cyclophosphamide but developed acute myeloblastic leukaemia at the age $\sigma$ of 72 from which he succumbed in three months and 0 they suggested that the leukaemia might have been $\frac{\$}{0}$ induced by therapy; Osserman and Lawton (1966) 0 and Nordenson (1966) had each reported cases of $\stackrel{ }{\supset}$ myeloblastic leukaemia in myeloma patients but had $\vec{c}$ not raised the possibility that it might be iatrogenic. $\frac{\mathbb{O}}{0}$ Since then there have been a number of reports (we $\stackrel{\vec{D}}{\vec{D}}$ have seen two such cases) of acute leukaemia, usually $\frac{3}{\sigma}$ myelomonocytic, arising in patients under treatment $\stackrel{\mathbb{Q}}{\square}$ for myelomatosis (Kyle, Pierre, and Bayrd, 1970; $\overrightarrow{0}$ Holland, 1970; Anderson and Videboek, 197థ; $\omega$ British Medical Journal, 1971; Scamps, O’Neill, and Newland, 1971); melphalan has been most commonf used but cyclophosphamide has also been given and Scamps et al (1971) pointed out that leukaemia has usually arisen in those patients who had responded $\stackrel{\mathcal{D}}{\mathscr{Q}}$ to therapy.

Bösken and Noltenius (1968) were the first to $\overrightarrow{\bar{O}}$ suggest that chemotherapy might induce sarcomatous change in the dysproteinaemias. Their patient was a man aged 72 at death, who had been under observation for nearly 30 years with a haemorrhagic diathesis and dysproteinaemia which was recognized in 1959 as an example of Waldenström's macroglobulinaemia and treatment was instituted with $\delta$ cyclophosphamide $800 \mathrm{mg}$ a week. By 1964 there was symptomatic improvement, the serum protein 음 returned to normal and the abnormal lymphoid cells $>$ had disappeared from the bone marrow and this remission persisted for three years, but six months $N$ before death, the patient became dyspnoeic with increasing pulmonary shadows and cachexia. Post- $N$ mortem examination revealed tumours in the lungs, liver, kidney, and lymph nodes which on microscopy were found to be poorly differentiated pleomorphic 6 reticulosarcoma, but there was no abnormality in the $\mathbb{\Phi}$ bone marrow.

The three cases reported here had all responded 0 well to chemotherapy (two had received cyclophos- 0 ) phamide, the third melphalan and radiotherapy) and $\stackrel{\Phi}{\Phi}$ at necropsy it was only possible to find small foci of $\stackrel{\mathbb{Q}}{\varrho}$ 
myeloma plasma cells in the marrow. In view of the evidence which has accumulated it would be reasonable to postulate that the chemotherapy had induced the reticulosarcomatous change rather than to suggest that reticulosarcomatous change is liable to arise as a complication of myelomatosis if survival is long enough. The iatrogenic hypothesis is to some extent supported by the fact that before 1960 very few cases of reticulosarcoma in association with myelomatosis cases of reticulosarcoma in association with myelomatosis have been reported and since then the majority of such cases had a good initial response to chemotherapy.

The three cases were included in M.R.C. Trials on myeloma and we are grateful to Professor Hobbs who provided the immunoglobulin data. They were also mentioned in a communication on 'Multiple myeloma-development of alternative malignancy following successful chemotherapy' given by J. M. Holt, A. H. T. Robb-Smith, S. T. Callender, and A. I. Spriggs to the British Society of Haematology in January 1972 of which a brief abstract was published in the British Journal of Haematology (1972, 22, 633).

\section{References}

Aherne, W. A. (1961). Myelomatosis-a clinical and pathological study. MD Thesis, National University of Ireland.

Anderson, E., and Videboek, A. (1970). Stem cell in leukaemia in myelomatosis. Scand. J. Haemat., 7, 201-207.

Bösken, W., and Noltenius, H. (1968). Groszelliges Reticulum zellsarkom als spătzustand einer endoxanbehandelten Makroglobulinämie Waldenström. Zlb. allg. Path. path. Anat., 111, 407-413.

British Medical Journal (1971). Leukaemia on myeloma. Editorial 1, 568-569.

Carson, C. P., Ackerman, L. V., and Maltby, J. D. (1955). Plasma cell myeloma. Amer. J. clin. Path., 25, 849-888.

Chiari, H. (1964). Uber eigentümliche Verlaufsformen von Haemoblastosen. Beitr. path. Anat., 130, 51-68.

Churg, I., and Gordon, A. J. (1950). Multiple Myeloma: lesions of the extra-osseous hematopoietic system. Amer.J. clin. Path., 20, 934-945.

Craft, I. L. (1967). The late appearance of extramedullary lesions in myelomatosis. Brit. J. Cancer, 21, 501-504.

Doak, P. B., Montgomerie, J. Z., North, J. D. K., and Smith, F. (1968). Reticulum cell sarcoma after renal homotransplantation and azathioprine and prednisone therapy. Brit. med. J., 4, 746-748.
Dolin, S., and Dewar, J. P. (1957). Extramedullary plasmacytoma. Amer. J. Path., 32, 83-103.

Edwards, G. A., and Zawadski, Z. A. (1967). Extraosseous lesions in plasma cell myeloma. Amer. J. Med., 43, 194-205.

Gross, U. M. (1964). Therapeutische induzierte polyblastische Reticulosen. Verh. dtsch. path. Ges., 48, 135-140.

Hayes, D. W., Bennett, W. A., and Heck, F. J. (1952). Extramedullary lesions in multiple myeloma. Arch. Path., 53, 262-272.

Hellwig, C. A. (1943). Extramedullary plasma cell tumours as observed in various locations. Arch. Path., 36, 95-111.

Holland, J. F. (1970). Epidemic acute leukemia. New Engl. J. Med., $283,1165-1166$.

Innes, J., and Newall, J. (1961). Myelomatosis. Lancet, 1, 239-245.

James, T. G. I., and Turner, E. A. (1952). Soft tissue involvement in multiple myelomatosis. Brit. J. Surg., 39, 361-364.

Kernen, J. A., and Meyer, B. W. (1966). Malignant plasmocytoma of the lung with metastases. J. thorac. cardiovasc. Surg., 51, 739-744.

Kyle, R. A., Pierre, R. V., and Bayrd, E. P. (1970). Multiple myeloma and acute myelomonocytic leukemia. New Engl. J. Med., 283 1121-1125.

Levin, H. A., Freeman, R. G., Smith, F. E., and Lane, M. (1967). Multiple extramedullary plasmacytomas. Arch. Derm., 96, 456-461.

Medical Research Council (1969). Summary Report of a Working Party on Hypogammaglobulinaemia in the United Kingdom. Lancet, 1, 163-168.

Mundy, G. R., and Baikie, A. G. (1973). Myeloma treated with cytophosphamide and terminating in reticulum cell sarcoma. Med. J. Acta., 1, 1240-1241.

Newman, W., Diefenbach, W. C. L., Quinn, M., and Meyer, L. M. (1952). A case of acute plasma-cell leukemia supporting the concept of unity of plasmacellular neoplasia. Cancer (Philad.), $5,514-420$.

Nordenson, N. G. (1966). Myelomatosis: a clinical review of 310 cases. Acta med. scand., Suppl., 445, 178-186.

Okano, H., Azar, H. A., and Osserman, E. F. (1966). Plasmacytic reticulum cell sarcoma. Amer. J. clin. Path., 46, 546-555.

Osserman, E. F., and Lawlor, D. P. (1966). Serum and urinary lysozyme (muramidase) in monocytic and monomyelocytic leukemia. J. exp. Med., 124, 921-925.

Pappenheim, A. (1907). Uber den Begriff des Myeloms... Folia haemat., 4, Suppl., 215-222.

Pasmantier, M. W., and Azar, H. A. (1969). Extraskeletal spread in multiple plasma cell myeloma. Cancer (Philad.), 23, 167-174.

Reinshagen, G. (1966). Lymphknotenplasmocytom der Axilla bei multiple Myelom. Beitr. path. Anat., 133, 395-408.

River, G. L., and Schorr, W. F. (1966). Malignant skin tumors in multiple myeloma. Arch. Derm., 93, 432-438.

Sandkühler, St., and Roemheld, L. (1957). Myelome mit plasmozytärem Pleuraerguss. Acta haemat. (Basel), 18, 403-413.

Scamps, R. A., O'Neill, B. J., snd Newland, R. C. (1971). A case of multiple myeloma terminating with acute myelomonocytic leukaemia. Med. J. Aust., 2, 1129-1130.

Terbrüggen, A. (1965). Neoplastische reticulose nach zytostatischer Dauerbehandlung von radikal operierten Karzinomen. Verh. dtsch. path. Ges., 49, 241-245.

Waldenström, J. (1964). Melphalan therapy in myelomatosis. Brit. med. J., 1, 859-865.

Wuketich, S., and Siegmund, G. (1961). Multiples Plasmozytom mit uebergang in riesenzelliges Retikulosarkom. Wien. klin. Wschr. 73, 473-476. 